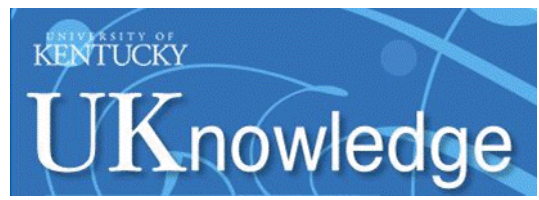

University of Kentucky

UKnowledge

Sanders-Brown Center on Aging Faculty

Publications

Aging

8-2016

\title{
Diabetes Is Associated with Cerebrovascular but not Alzheimer's Disease Neuropathology
}

\author{
Erin L. Abner \\ University of Kentucky, erin.abner@uky.edu \\ Peter T. Nelson \\ University of Kentucky, pnels2@uky.edu \\ Richard J. Kryscio \\ University of Kentucky, kryscio@uky.edu \\ Frederick A. Schmitt \\ University of Kentucky, fascom@uky.edu \\ David W. Fardo \\ University of Kentucky, david.fardo@uky.edu \\ Sellowe this and add ditionalworks,at:https://uknowledge.uky.edu/sbcoa_facpub \\ Part of the Biostatistics Commons, Epidemiology Commons, Geriatrics Commons, Medical Pathology \\ Commons, and the Neurology Commons \\ Right click to open a feedback form in a new tab to let us know how this document benefits you.
}

\section{Repository Citation}

Abner, Erin L.; Nelson, Peter T.; Kryscio, Richard J.; Schmitt, Frederick A.; Fardo, David W.; Woltjer, Randall L.; Cairns, Nigel J.; Yu, Lei; Dodge, Hiroko H.; Xiong, Chengjie; Masaki, Kamal; Tyas, Suzanne L.; Bennett, David A.; Schneider, Julie A.; and Arvanitakis, Zoe, "Diabetes Is Associated with Cerebrovascular but not Alzheimer's Disease Neuropathology" (2016). Sanders-Brown Center on Aging Faculty Publications. 63. https://uknowledge.uky.edu/sbcoa_facpub/63

This Article is brought to you for free and open access by the Aging at UKnowledge. It has been accepted for inclusion in Sanders-Brown Center on Aging Faculty Publications by an authorized administrator of UKnowledge. For more information, please contact UKnowledge@lsv.uky.edu. 


\section{Diabetes Is Associated with Cerebrovascular but not Alzheimer's Disease Neuropathology}

Digital Object Identifier (DOI)

http://dx.doi.org/10.1016/j.jalz.2015.12.006

\section{Notes/Citation Information}

Published in Alzheimer's \& Dementia, v. 12, issue 8, p. 882-889.

() 2016 The Alzheimer's Association. Published by Elsevier Inc. All rights reserved.

This manuscript version is made available under the CC-BY-NC-ND 4.0 license

https://creativecommons.org/licenses/by-nc-nd/4.0/

\section{Authors}

Erin L. Abner, Peter T. Nelson, Richard J. Kryscio, Frederick A. Schmitt, David W. Fardo, Randall L. Woltjer, Nigel J. Cairns, Lei Yu, Hiroko H. Dodge, Chengjie Xiong, Kamal Masaki, Suzanne L. Tyas, David A. Bennett, Julie A. Schneider, and Zoe Arvanitakis 
(C) 2016 The Alzheimer's Association. Published by Elsevier Inc. All rights reserved.

This manuscript version is made available under the CC-BY-NC-ND 4.0 license http://creativecommons.org/licenses/by-ncnd $/ 4.0 /$ 
Title: Diabetes is associated with cerebrovascular but not Alzheimer neuropathology

Authors: *Erin L. Abner ${ }^{a, b}$, Peter T. Nelson ${ }^{a}$, Richard J. Kryscio ${ }^{a, b}$, Frederick A. Schmitt ${ }^{a}$, David W. Fardo ${ }^{b}$, Randall L. Woltjer ${ }^{c}$, Nigel J. Cairns ${ }^{d}$, Lei Yu ${ }^{e}$, Hiroko H. Dodge ${ }^{c}$, Chengjie Xiong ${ }^{d}$, Kamal Masakif , Suzanne L. Tyas $^{\mathrm{g}}$, David A. Bennett ${ }^{\mathrm{e}}$, Julie A. Schneider ${ }^{\mathrm{e}}$,Zoe Arvanitakis ${ }^{\mathrm{e}}$

\section{Author affiliations:}

a. Sanders-Brown Center on Aging and Alzheimer's Disease Center, University of Kentucky, $800 \mathrm{~S}$. Limestone St, Lexington, KY, 40536, USA

b. College of Public Health, University of Kentucky, 111 Washington Ave, Lexington, KY, 40536

c. Layton Aging and Alzheimer's Disease Center, Oregon Health \& Science University, 3303 SW Bond Ave., Portland, OR, 97239, USA

d. Knight Alzheimer's Disease Research Center, Washington University, 4488 Forest Park Ave, St. Louis, MO, 63108, USA

e. Rush Alzheimer's Disease Center, Rush University Medical Center, 600 S. Paulina St, Chicago, IL, 60612, USA

f. Kuakini Medical Center and John A. Burns School of Medicine, University of Hawaii, 651 Ilalo St, Honolulu, HI, 96813, USA

g. School of Public Health and Health Systems, University of Waterloo, 200 University Ave W, Waterloo, ON, N2L 3G1, Canada

\section{Communicating author:}

Erin Abner, PhD

230 A Sanders-Brown Center on Aging

University of Kentucky

Lexington, KY 40536-0230 USA

Work ph: 859-218-3825

erin.abner@uky.edu 


\section{Abstract}

INTRODUCTION: Diabetes' relationship to specific neuropathological causes of dementia is incompletely understood.

METHODS: We used logistic regression to evaluate the association between diabetes and infarcts, Braak stage, neuritic plaque score, and level of Alzheimer's neuropathological changes in 2,365 autopsied persons. In a subset of $>1,300$ persons with available cognitive data, we examined the association between diabetes and cognition using Poisson regression.

RESULTS: Diabetes increased odds of brain infarcts (OR=1.57, $P<0.0001)$, specifically lacunes (OR=1.71, $P<0.0001)$, but not Alzheimer neuropathology. Diabetes plus infarcts was associated with lower cognitive scores at end of life than infarcts or diabetes alone, and diabetes plus high level of Alzheimer's neuropathological changes was associated with lower MMSE scores than the pathology alone.

DISCUSSION: This study supports the conclusions that diabetes increases the risk of cerebrovascular but not Alzheimer's pathology, and at least some of diabetes' relationship to cognitive impairment may be modified by neuropathology.

Keywords: diabetes, neuropathology, infarcts, autopsy, cognition, cerebrovascular, Alzheimer

Abbreviations: SMART: Statistical Modeling of Aging and Risk of Transition study; BRAiNS: Biologically Resilient Adults in Neurological Studies; ROS: Religious Orders Study; HAAS: Honolulu-Asia Aging Study; mABC: modified Alzheimer's disease neuropathologic change rating based on $\underline{A} \beta$ plaque score, $\underline{B}$ raak NFT (neurofibrillary tangle) stage, and CERAD NP (neuritic plaque) score. 


\section{Introduction}

A strong body of evidence links diabetes to cognitive dysfunction and dementia, including clinically diagnosed Alzheimer's disease (AD) and vascular dementia. Insulin resistance [1-3] and glucose levels [4] have both been suggested as driving factors in the diabetes-dementia relationship. Many researchers argue that diabetes and AD are closely linked, with shared biochemical etiologies [5], and these hypotheses are supported by epidemiological studies that identified increased incidence of clinical AD for people with diabetes [6-9]. Positron emission tomography (PET) imaging shows evidence of glucose metabolic changes early in life among individuals at risk for developing $A D$ [10]. Neuroimaging studies have reported conflicting results regarding insulin resistance: Willette and colleagues (2015) [10] reported increased amyloid deposition in normoglycemic, late middle-aged adults with higher levels of insulin resistance [11], while Thambisetty and colleagues (2013) reported no association [12]; both studies used 11C-Pittsburgh compound B PET, although insulin resistance was measured differently. Insulin resistance has also been reported to be associated with higher cerebrospinal fluid tau levels in APOE- $\varepsilon 4$ allele carriers [13] and is increased in brain tissue in early AD [14].

Despite data linking diabetes and clinical $A D$, there are strong arguments that diabetes may not exacerbate AD neuropathology. Clinicopathological studies have largely been unable to demonstrate higher burden of AD neuropathology in persons with diabetes [15-18], except perhaps in APOE- 4 allele carriers [7, 9]. By contrast, studies often report increased cerebrovascular pathology [7, 9, 17]. Epidemiological, clinical, and neuroimaging studies have also identified increased risk of cerebrovascular disease (CVD) linked to diabetes [19-21].

We re-examined the association between diabetes and neuropathology in a large clinicopathological study (>2,000 total autopsies) drawn from the Statistical Modeling of Aging and Risk of Transition (SMART) database, a consortium of longitudinal studies of aging and cognition [22]. We assessed AD neuropathology and cerebral infarctions in aged participants with and without diabetes, 
controlling for age at death, sex, research center, and other potential confounders in a series of regression models. We also evaluated the relative impact of diabetes on cognition using Mini-Mental State Exam (MMSE) and Animal Naming Test (Animals) scores obtained near death.

\section{Methods}

\subsection{Sample}

Cases were drawn from participants in the SMART database [22]. Briefly, the database comprises a standardized set of data elements contributed by 11 longitudinal studies of aging and cognition. Most included cohorts have lengthy follow-up and high autopsy rates. Cohorts that required or encouraged brain donation and collected information on diabetes are included in the current study. Since not all deceased participants came to autopsy, and not all autopsies were included in the current study, we assessed selection bias by comparing the included participants to all deceased participants in the included cohorts with respect to age at death, gender, APOE- $\varepsilon 4$, cohort, and diabetes. Inclusion criteria for the current study were known diabetes status and non-missing data on at least one neuropathological measure of both Alzheimer's disease (either Braak neurofibrillary tangle [NFT] stage [23] or Consortium to Establish a Registry in Alzheimer's Disease [CERAD] neuritic plaque [NP] rating [24]), and infarct neuropathology (large artery infarcts, lacunes, or microinfarcts). Based on availability of necessary variables, participants from the following cohorts were included: Honolulu-Asia Aging Study (HAAS) [25], Oregon Brain Aging Study [26], African American Dementia Project (see [22]), Klamath Exceptional Aging Project [27], Religious Orders Study (ROS) [28], Rush Memory and Aging Project (Rush MAP) [29], Memory and Aging Project at Washington University [30], and Biologically Resilient Adults in Neurological Studies (BRAiNS) [31]. Research procedures were approved by Institutional Review Boards at each cohort's home institution. All participants provided written informed consent. 


\subsection{Determination of diabetes}

We determined diabetes status by self-report or by reported use of antidiabetic medication, as previously described in ROS [32], Rush MAP [33], HAAS [7], and BRAiNS [34]. Although Type 1 and Type 2 diabetes were not differentiated, given the rarity of Type 1 diabetes in participants over age 60 and especially over age 80 [35], we assumed that diabetes reports comprised Type 2 diabetes (hereafter

"diabetes"). Laboratory blood measures were not available in the SMART database, and therefore were not examined in the present study.

\subsection{Neuropathological outcomes}

Autopsies were conducted within the original cohort studies [25, 26, 30, 31, 36, 37]. The association between diabetes and neuropathology has been examined previously in some included cohorts-HAAS [7], ROS [32], and BRAiNS [34] - but new endpoints are assessed and many additional participants are included in the current study. Neuropathological assessments were performed blind to clinical data. Neuropathological data were scored according to a format of the National Alzheimer's Coordinating Center (NACC) dataset, as described previously [22], because most SMART neuropathologists contribute to NACC (see https://www.alz.washington.edu/NONMEMBER/NP/rdd_np.pdf). Briefly, study neuropathologists made determinations of Braak NFT stage [23]; CERAD NP rating (None, Sparse, Moderate, or Frequent) [24]; diffuse plaque rating (None, Sparse, Moderate, or Frequent); and presence of large artery cerebral infarcts, lacunes, and cortical microinfarcts. "Large" infarcts were defined as any infarct with maximum diameter greater than $1 \mathrm{~cm}$; lacunes were defined as infarcts or hemorrhages $1 \mathrm{~cm}$ or less in diameter in the small parenchymal vessels, but visible to the naked eye; and microinfarcts were defined as cortical infarcts detected microscopically only. 
Since Thal phases ( $A \beta$ immunohistochemistry) were unavailable, we constructed a modified version of the National Institute on Aging-Alzheimer's Association criteria for AD neuropathological change (the "ABC" score) [38], that addressed the cases where diffuse amyloid plaque neuropathology may be present without neuritic amyloid plaques. Thus, we collapsed the concept of diffuse amyloid deposits to a dichotomous " $A_{d}$ " variable. We considered the presence of any diffuse plaques to be $A_{d}=1$, while absence of any diffuse plaques was 0 . High level of AD changes corresponded to an $A_{d}$ score of 1 plus Braak NFT stage V/VI plus CERAD NP rating of Frequent or Moderate. Intermediate level of AD changes corresponded to an $A_{d}$ score of 1 plus either Braak NFT stage V/VI plus None or Sparse CERAD NP or Braak III/IV plus Frequent or Moderate CERAD NP. Low level of AD changes corresponded to an $A_{d}$ score of 1 plus either Braak NFT stage III/IV plus None or Sparse CERAD NP or Braak NFT stage 0/I/II. No $A D$ changes corresponded to an $A_{d}$ score of 0 (absence of diffuse plaques) to enable compatibility with the new consensus-based diagnostic criteria.

\subsection{Covariates}

Participant age at death (centered at 85 years), sex (female=1, male=0), education (years), APOE- $\varepsilon 4$ carrier status (any $\varepsilon 4$ alleles $=1$, no $\varepsilon 4$ alleles $=0$ ), hypertension (yes=1, no=0), and research center were included as potential confounders.

\subsection{Cognitive data}

Global cognition was estimated using the MMSE [39] and category fluency using Animals [40] in participants for whom those scores were available. Two sets of scores were examined: scores obtained within two years of death, and scores obtained six years prior to death. MMSE and Animals were selected because all cohorts administered Animals, and all cohorts except for one administered the MMSE. 


\subsection{Statistical Analysis}

All statistical analyses were performed using SAS $9.4^{\circledR}$ (SAS Institute, Inc; Cary, NC). Two-group comparisons of potential confounding variables for participants with and without diabetes were made using $t$ tests for interval-level variables and chi-square tests for categorical variables. We used casecontrol designs, where cases demonstrated the neuropathological outcome of interest and controls were free of the neuropathology, to estimate adjusted odds ratios (OR) and $95 \%$ confidence intervals (Cl) for the association between neuropathological outcomes and diabetes. For multi-level variables (mABC rating, Braak NFT stage, and CERAD NP score), we used the "absent" category (e.g., CERAD NP score of 'None') as the reference level and computed an OR for each stratum separately; we conducted sensitivity analyses using ordinal logistic regression models.

To address confounding, we used logistic regression to estimate adjusted ORs. For each dependent neuropathological measure, we constructed two models. The first model included control variables age at death, sex, and center. The second model included these variables plus education, hypertension, and APOE- $\varepsilon 4$ status. There was a loss in sample size in the second model due to missing data in some of the additional variables. Significance for neuropathological models was set at 0.05 , but we also used the Holm-Bonferroni procedure to assess the robustness of the results given there were 26 comparisons made.

Last, we evaluated the association between diabetes and end-of-life global cognition and category fluency. We estimated mean scores using Poisson regression and controlled for neuropathology ( $\mathrm{mABC}$ rating, and, in separate models, any infarcts or lacunes). Interactions between diabetes and neuropathology were tested in the initial models. We adjusted mean scores for age at death, education, sex, center, and time (in years) since last assessment. Given the lengthy follow-up of most SMART cohorts, we also examined adjusted mean MMSE and Animals scores for participants with 
scores available six years prior to death. Assessments that occurred between 5.5 and 6.5 years prior to death were included in this analysis. Significance for cognitive models was set at 0.05.

\section{Results}

There were 6,143 deaths in the included cohorts. Of the 2,429 total autopsies, 2,365 (97.4\%) were included in the current study. Participant inclusion is shown in Figure 1. Probability of inclusion in the present study, conditioned on death, was independent of diabetes and depended only on cohort $(P<0.0001)$, since cohorts had different protocols for obtaining brain donation, and on age, such that a 1year increase in age at death increased the odds of inclusion by about $1 \%(P=0.048)$. Sex, APOE, and diabetes status had no association with the probability of inclusion in the study after controlling for cohort.

Participants with diabetes ( $n=507 ; 21.4 \%$ of total sample) died younger, had lower educational attainment, and were more likely to have hypertension than participants without diabetes $(n=1,858)$ (Table 1). Last cognitive diagnosis was similar by diabetes status, and where dementia subtype was classified, proportions of clinical AD ( $68 \%$ vs. $73 \%$ ) and vascular dementia ( $29 \%$ vs $22 \%$ ) were similar in participants with and without diabetes, respectively $(P=0.33)$. APOE- $\varepsilon 4$ carrier status was similar among those with and without diabetes. APOE was missing in $1.8 \%$ of cases with and in $2.2 \%$ of cases without diabetes. Because participants without diabetes were almost twice as likely to be missing hypertension (7.9\% vs. $4.3 \%$ ), we performed a sensitivity analysis that assumed all missing cases in the no diabetes group had hypertension; the proportion with hypertension in the diabetes group remained significantly higher than in those without diabetes $\left(\chi^{2}=36.2, P<0.0001\right)$. Diabetes was reported during follow-up for an average of $6.8 \pm 4.6$ years.

Neuropathological outcome measures were incompletely observed in only a small proportion of cases, with the exception of microinfarcts, which were missing in $23 \%$ of participants with diabetes 
(Table 2). Participants with diabetes had an estimated $54-57 \%$ increased odds of having any infarct $(P<0.0001$ in Model 1; $P=0.001$ in Model 2$)$ and had an estimated $71-77 \%$ increased odds of having lacunes $(P<0.0001$ in both models) (Table 3). Prevalence of large infarcts and microinfarcts did not differ by diabetes status, but participants with diabetes had marginally increased odds of having three infarct types observed ( $P=0.05$, Model $1 ; P=0.04$, Model 2$)$. There was no statistically significant association with $A D$ neuropathology, although there was some evidence that Low or Intermediate level of AD neuropathology (vs. None) may be more common among participants with diabetes (Table 3). Results were similar when we used ordinal rather than stratified logistic models (data not shown).

The association of diabetes with cognitive scores was modified by presence of any infarcts ( $P=0.0016$ for interaction; see Table 4 for means). Specifically, diabetes was associated with end-of-life global cognition (MMSE) and category fluency (Animals) for participants with any infarcts. The presence of diabetes in the absence of any infarcts was not associated with worse scores on either measure, but participants who had both diabetes and any infarcts were significantly worse on both measures than participants with infarcts alone (MMSE: $\Delta=-1.1$ points, $P=0.0002$; Animals: $\Delta=-0.6$ points, $P<0.0001$ ). Results were similar for lacunes (Table 4). For participants with 'High' mABC rating, diabetes was associated with lower MMSE scores than participants with 'High' mABC but without diabetes (14.3 vs. 16.1; $P=0.0008) ;$ MMSE scores did not vary by other levels of $\mathrm{mABC}$ according to diabetes status. There was no difference in Animals scores associated with diabetes and $\mathrm{mABC}(P=0.27)$. When neuropathology was removed from the models, diabetes had no significant effect on either mean MMSE or Animals scores. For assessments made six years prior to the end of life diabetes had no effect on mean MMSE or Animals scores, either by modifying the effect of neuropathology, which was specified identically to the previous models, or as a main effect (data not shown). As with end-of-life scores, diabetes had no significant association with mean MMSE or Animals scores obtained six years prior to death when neuropathology was removed from the models. In a sensitivity analysis examining slopes of change 
between two and six years before death, we found no mean differences associated with diabetes (data not shown).

\section{Discussion}

Results from this autopsy study of about 2,400 older persons with and without diabetes, the largest to date, confirm that diabetes is significantly associated with brain infarction, specifically lacunes. We also found that diabetes in combination with infarcts was associated with lower MMSE and Animals scores at the end of life compared to infarcts alone. By contrast, in this large sample, there was little evidence that diabetes was associated with any $A D$ neuropathology measure (global or more specific measures). For participants with the highest level of AD changes, diabetes was associated with lower mean MMSE but not Animals scores.

The link between diabetes and CVD has been demonstrated repeatedly in the scientific, including epidemiologic, literature [19, 41-43]. The mechanisms through which diabetes causes CVD remain incompletely understood, but may involve insulin resistance, high fasting blood glucose, hypertension, comorbid abdominal obesity, carotid disease, endothelial dysfunction, and hypercoagulation, among other mechanisms (see [44] for a review).

Neuropathological studies have repeatedly identified increased CVD, specifically brain infarction, in association with diabetes, $[9,17,32,34]$. However, the results are somewhat more heterogeneous than this statement suggests. Sonnen and colleagues reported increased microvascular infarcts in persons with diabetes, but only when dementia was also present [17]. Similarly, Nelson and colleagues reported increased microinfarcts but without regard to cognitive status [34]. They also reported an increase in the presence of any infarct (including large infarcts, lacunes, microinfarcts, and hemorrhagic infarcts). By contrast, Arvanitakis and colleagues [32] and Ahtiluoto and colleagues [9] identified macroscopic infarcts, visible to the naked eye, regardless of size, and found a positive 
association. In the current study, we found that diabetes was associated with any infarct (any large infarct, lacune, and/or microinfarct) and also lacunes specifically. An association between diabetes and lacunes has also been reported in neuroimaging studies [45]. Although we did not find a relationship between microinfarcts and diabetes such as has been previously reported [17, 34], the substantial proportion of missing data on microinfarcts in participants with diabetes compared to those without ( $23 \%$ vs $12 \%, P<0.0001)$ may affect comparability.

As with CVD, epidemiologic studies have largely identified increased risk of AD for people with diabetes [6-9], although some have not $[42,46]$. In experimental studies, including in postmortem human tissue, brain insulin resistance has been identified as a feature of early AD [14], and abnormal serine phosphorylation of insulin receptor substrate 1 was shown to be elevated in AD brains $[3,47]$ and to be associated with pathologic tau in neurons [47]. Animal studies have reported that anti-diabetes agents may protect against $A \beta$-induced defective insulin signaling [3] and reverse increases in $A \beta$ levels induced through high-fat diet [48].

Two autopsy-based studies of diabetes or related measures reported increased AD neuropathology. Peila et al. [7] examined 216 cases from HAAS (a subset of the 769 cases from HAAS included in the present study) and reported increased NFT in the hippocampus and cortex and increased NP in the hippocampus for participants with both diabetes and APOE- $\varepsilon 4$ allele, compared to participants without either factor. This group did not have increased AD neuropathology compared to participants with APOE- $\varepsilon 4$ alone. Participants with diabetes alone did not have increased AD neuropathology on any measure compared to participants without either factor. Matsuzaki et al. [1] reported on 135 autopsies from participants in a population-based study of residents in Hisayama, Japan. Blood-based measures of diabetes obtained 10-15 years prior to death were used to predict Braak stage and CERAD NP score. No associations with Braak stage were detected, but increases in 2-hour post-challenge glucose, fasting 
insulin, and insulin resistance were associated with increased odds of any NP (but no graded effect for increased NPs). APOE- $\varepsilon 4$ plus hyperglycemia also increased odds of any NP.

Most studies with autopsy-verified measures have not supported a positive association between diabetes and amyloid or tau neuropathology. The absence of an autopsy-verified diabetes-AD relationship in these studies is conspicuous, considering that $A D$ markers were measured and quantified with a variety of techniques, including immunocytochemistry [15], immunohistochemistry [7, 9, 16, 32, 34], silver staining [9, 32, 34], and biochemical analysis [17]. Moreover, the lack of positive association between diabetes and frequency or severity of AD neuropathology is independent of the operationalization of neuropathology: Braak NFT staging $[15,17,34]$, NFT density $[9,18,32,34]$, CERAD NFT [16] and NP ratings $[15,16,17,34]$, NP density $[9,18,34], \beta$-amyloid protein burden $[9,32]$, and, here, modified $A B C$ rating.

In addition to the association of diabetes with brain infarction, we also found that diabetes, in combination with any brain infarction, as well as lacunes specifically, was associated with significantly lower MMSE and Animals scores at the end of life. It is unclear why diabetes was associated with cognitive impairment only near death, and future research should address more directly the temporal relationship between diabetes and cognitive outcomes. We did not find a strong relationship to cognition for diabetes alone or in combination with $\mathrm{mABC}$ score, although participants with 'High' mABC and diabetes had significantly lower MMSE scores, but not Animals scores, than participants with 'High' $\mathrm{mABC}$ but without diabetes. However, results pertaining to cognitive scores should be interpreted with caution. Participants with diabetes were more likely to be missing MMSE scores (26.6\% vs. $18.0 \%$ missing, $P<0.0001)$, and participants with missing Animals scores tended to be older. For both instruments, participants with missing data were less educated, were more likely to have any infarcts and were less likely to have high or intermediate $\mathrm{mABC}$ rating (data not shown). 
Our study has several strengths. This is the largest study to date of diabetes and neuropathology of $A D$ and CVD. We used data from detailed neuropathological assessments. This is the first study, to our knowledge, to examine the association between diabetes and $A B C$ rating. We also used other established methods to diagnose or stage AD neuropathology. There was no evidence of selection bias with regard to sex, education, APOE, or diabetes status within each cohort.

This study has some limitations. This is an observational study, and causal relationships cannot be established. Although we controlled for confounding factors, we did not have available data on adiposity or smoking habits; smoking is likely related to both risk of cerebrovascular pathology and other lifestyle factors that may be related to diabetes. Diabetes was ascertained via self-report and medication inspection rather than laboratory blood measures, so cases were likely missed. We used semiquantitative rather than quantitative measures of neuropathology, but as noted above findings in this area have been rather consistent independent of the neuropathological methods used. We used a modified $A B C$ rating due to unavailability of Thal phases; this may have resulted in a very small proportion of cases receiving a different $A B C$ classification than they would have otherwise. This study combined autopsied cases assessed by multiple neuropathologists, who may have had slightly different criteria for classifying neuropathology. However, we also view this as a strength because a multi-center approach, which synthesizes findings from multiple pathologists, approximates the experience of community neuropathologists. Finally, our findings may not be generalizable to the general older adult population given the differences in recruitment methods and source populations in each cohort. Nonetheless, overall the findings are consistent with previous literature.

Based on our results, and the results of many prior clinicopathological studies, diabetes, measured as a dichotomous variable, is unlikely to be significantly associated with AD neuropathology but is likely to be significantly associated with CVD pathology. However, diabetes is heterogeneous. Individuals differ in disease severity and duration, treatments used, comorbidities, and lifestyle factors. 
More research is needed to better account for these complicating factors, as well as survival bias or perhaps compensatory mechanisms that may be at play, and identify subgroups that may be at increased risk for AD.

Acknowledgements. We are grateful to our participants and their families. We thank Robin Guariglia, Randi Chen, Elizabeth Washington, and John Gibbons for their assistance in preparing the SMART data.

Funding. SMART is supported by NIA grant R01-AG038651. Cohort studies were supported by NIA grants P30-AG10161 and R01-AG15819 (ROS), R01-AG17917 (Rush MAP), P30-AG028383 (BRAiNS), P50AG005681 (Wash U MAP), P30-AG008017 (OBAS, KEAP, AADAPt). HAAS Funding: NHLBI contract N01HC-05102, NIA contract N01-AG-4-2149, NIA grants U01-AG019349 and U01-AG017155, Kuakini Medical Center, Hawaii Community Foundation grant 2004-0463, and the Office for Research and Development, Department of Veterans Affairs. Other support includes NINDS grant R01-NS084965. Sponsors played no role in the design or analysis of this study. 


\section{References}

[1] T. Matsuzaki, K. Sasaki, Y. Tanizaki, J. Hata, K. Fujimi, Y. Matsui, A. Sekita, S.O. Suzuki, S. Kanba, Y. Kiyohara, T. Iwaki. Insulin resistance is associate with the pathology of Alzheimer disease: the Hiyasama study. Neurology 2010;75:764-70.

[2] B. Cholerton, L.D. Baker, S. Craft. Insulin, cognition, and dementia. Eur J Pharmacol 2013;719:170-9.

[3] T. R. Bonfim, L. Forny-Germano, L.B. Sathler, J. Brito-Moreira, J.C. Houzel, H. Decker, M.A. Silverman, H. Kazi, H.M. Melo, P.L. McClean, C. Holscher, S.E. Arnold, K. Talbot, W.L. Klein, D.P. Munoz, S.T. Ferreira, F.G. De Felice. An anti-diabetes agent protects the mouse brain from defective insulin signaling caused by Alzheimer's disease-associated A $\beta$ oligomers. J Clin Invest 2012;122:1339-53.

[4] P.K. Crane, R. Walker, R.A. Hubbard, G. Li, D.M. Nathan, H. Zheng, S. Haneuse, S. Craft, T.J. Montine, S.E. Kahn, W. McCormick, S.M. McCurry, J.D. Bowen, E.B. Larson. Glucose levels and risk of dementia. N Eng J Med 2013;369:540-8.

[5] S.M. de la Monte, J.R. Wands. Alzheimer's disease is Type 3 diabetes-Evidence reviewed. J Diabetes Sci Technol 2008;3:1101-13.

[6] J.A. Luchsinger, M.X. Tang, Y. Stern, S. Shea, R. Mayeux. Diabetes mellitus and risk of Alzheimer's disease and dementia with stroke in a multiethnic cohort. Am J Epidemiol 2001;154:635-641.

[7] R. Peila, B.L. Rodriguez, L.J. Launer. Type 2 diabetes, APOE gene, and the risk for dementia and related pathologies. The Honolulu-Asia Aging Study. Diabetes 2002;51:1256-62.

[8] F. Irie, A.L. Fitzpatrick, O.L. Lopez, L.H. Kuller, R. Peila, A.B. Newman, L.J. Launer. Enhanced risk for Alzheimer disease in persons with type 2 diabetes and APOE epsilon4: the Cardiovascular Health Study Cognition Study. Arch Neurol 2008;65:89-93.

[9] S. Ahtiluoto, T. Polvikoski, M. Peltonen, A. Solomon, J. Tuomilehto, B. Winblad, R. Sulkava, M. Kivipelto. Diabetes, Alzheimer disease, and vascular dementia. A population-based neuropathologic 
study. Neurology 2010;75:1195-1202.

[10] E.M. Reiman, K. Chen, G.E. Alexander, R.J. Caselli, D. Bandy, D. Osborne, A.M. Saunders, J. Hardy. Functional brain abnormalities in young adults at genetic risk for late-onset Alzheimer's dementia. Proc Natl Acad Sci 2004;101(1):284-9.

[11] A.A. Willette, S.C. Johnson, A.C. Birdsill, M.A. Sager, B. Christian, L.D. Baker, S. Craft, J. Oh, E. Statz, B.P. Hermann, E.M. Jonaitis, R.L. Koscik, A. La Rue, S. Asthana, B.B. Bendlin. Insulin resistance predicts brain amyloid deposition in middle-aged adults. Alzheimers Dement 2015;11:504-10.

[12] M. Thambisetty, E.J. Metter, A. Yang, H. Dolan, C. Marano, A.B. Zonderman, J. Troncoso, Y. Zhou, D.F. Wong, L. Ferrucci, J.M. Egan, S.M. Resnick, R. O’Brien. Glucose intolerance, insulin resistance and Alzheimer's disease pathology in the Baltimore Longitudinal Study of Aging. JAMA Neurol 2013;70:116772.

[13] E.J. Starks, J.P. O’Grady, S.M. Hoscheidt, A.M. Racine, C.M. Carlsson, H. Zetterberg, K. Blennow, O.C. Okonkwo, L. Puglielli, S. Asthana, N.M. Dowling, C.E. Gleason, R.M. Anderson, N.J. Davenport-Sis, L.M. DeRungs, M.A. Sager, S.C. Johnson, B.B. Bendlin. Insulin resistance is associated with higher cerebrospinal fluid tau levels in asymptomatic APOE $\varepsilon 4$ carriers. J Alzheimers Dis 2015 Mar 26. Epub ahead of print.

[14] K. Talbot, H. Wang, H. Kazi, L. Han, K.P. Bakshi, A. Stucky, R.L. Fuino, K.R. Kawaguchi, A.J. Somyedny, R.S. Wilson, Z. Arvanitakis, J.A. Schneider, B.A. Wolf, D.A. Bennett, J.Q. Trojanowski, S.E. Arnold. Demonstrated brain insulin resistance in Alzheimer's disease patients is associated with IGF-1 resistance, IRS-1 dysregulation, and cognitive decline. J Clin Invest 2012;1316-38.

[15] J. Heitner, D. Dickson. Diabetics do not have increased Alzheimer-type pathology compared with age-matched control subjects. A retrospective postmortmem immunocytochemical and histofluorescent study. Neurology 1997;49:1306-11. 
[16] M.S. Beeri, J.M. Silverman, K.L. Davis, D. Marin, H.Z. Grossman, J. Schmeidler, D.P. Purohit, D.P. Perl, M. Davidson, R.C Mohs, V. Haroutunian. Type 2 diabetes is negatively associated with Alzheimer's disease neuropathology. J Gerontol A Biol Sci Med Sci 2005;60:471-5.

[17] J.A. Sonnen, E.B. Larson, K. Brickell, P.K. Crane, R. Woltjer, T.J. Montine, S. Craft. Different patterns of cerebral injury in dementia with or without diabetes. Arch Neurol 2009;66:315-322.

[18] J. Janson, T. Laedtke, J.E. Parisi, P. O’Brien, R.C. Petersen, P.C. Butler. Increased risk of type 2 diabetes in Alzheimer's disease. Diabetes 2004;53:474-81.

[19] P.A. Wolf, R.B. D'Agostino, A.J. Belanger, W.B. Kannel WB. Probability of stroke: a risk profile from the Framingham Study. Stroke 1991;22:312-318.

[20] S. Rastas, T. Pirttila, K. Mattila, A. Verkkoniemi, K. Juva, L. Niinisto, E. Lansimies, R. Sulkava. Vascular risk factors and dementia in the general population aged $<85$ years. Prospective population-based study. Neurobiol Aging. 2010;31:1-7.

[21] M. Brundel, Y.D. Reijmer, S.J. van Veluw, H.J. Kujif, P.R. Luijten, L.J. Kappelle, G.J. Biessels. Cerebral microvascular lesions on high-resolution 7-Tesla MRI in patients with type 2 diabetes. Diabetes 2014;63:3523-29.

[22] E.L. Abner, F.A. Schmitt, P.T. Nelson, W. Lou, L. Wan, R. Gauriglia, H.H. Dodge, R.L. Woltjer, L. Yu, D.A. Bennett, J.A. Schneider, R. Chen, K. Masaki, M.J. Katz, R.B. Lipton, D.W. Dickson, K.O. Lim, L.S. Hemmy, N.J. Cairns, E. Grant, S.L. Tyas, C. Xiong, D.W. Fardo, R.J. Kryscio. The Statistical Modeling of Aging and Risk of Transition Project: Data Collection and Harmonization Across 11 Longitudinal Cohort Studies of Aging, Cognition, and Dementia. Observational Studies 2015;1: 56-73.

[23] H. Braak, E. Braak. Neuropathological stageing of Alzheimer-related changes. Acta Neuropathol 1991; 82:239-259. 
[24] S.S. Mirra, A. Heyman, D. McKeel, S.M. Sumi, B.J. Crain, L.M. Brownlee, F.S. Vogel, J.P. Hughes, G. van Belle, L. Berg. The Consortium to Establish a Registry for Alzheimer's Disease (CERAD). Part II. Standardization of the neuropathologic assessment of Alzheimer's disease. Neurology 1991;41:479-86. [25] R.P. Gelber, L.J. Launer, L.R. White. The Honolulu-Asia Aging Study: Epidemiologic and neuropathologic research on cognitive impairment. Curr Alzheimer Res 2012;9:664-72.

[26] M.S. Green, J.A. Kaye, M.J. Ball. The Oregon Brain Aging Study: Neuropathology accompanying healthy aging in the oldest old. Neurology 2000;54:105.

[27] J. Kaye, Y. Michael, J. Calvert, M. Leahy, D. Crawford, P. Kramer. Exceptional brain aging in a rural population-based cohort. J Rural Health 2009;25:320-5, 2009.

[28] D.A. Bennett, J.A. Schneider, A.S. Buchman, C. Mendes de Leon, J.L. Bienias, R.S. Wilson. The Rush Memory and Aging Project: Study design and baseline characteristics of the study cohort. Neuroepidemiology 2005;25:163-75.

[29] D.A. Bennett, J.A. Schneider, A.S. Buchman, L.L. Barnes, P.A. Boyle, R.S. Wilson. Overview and findings from the Rush Memory and Aging Project. Curr Alzheimer Res 2012;9:648-665.

[30] L. Berg, D.W. McKeel, J.P. Miller, M. Storandt, E.H. Rubin, J.C. Morris, J. Baty, M. Coats, J. Norton, A.M. Goate, J.L. Price, M. Gearing, S.S. Mirra, A.M. Saunders. Clinicopathologic studies in cognitively healthy aging and Alzheimer's disease. Relation of histologic markers to dementia severity, age, sex, and apolipoprotein E genotype. Arch Neurol 1998;55:326-35.

[31] F.A. Schmitt, P.T. Nelson, E. Abner, S. Scheff, G.A. Jicha, C. Smith, G. Cooper, M. Mendiondo, D.D. Danner, L.J. Van Eldik, A. Caban-Holt, M.A. Lovell, R.J. Kryscio. University of Kentucky Sanders-Brown Health Brain Aging Volunteers: Donor characteristics, procedures, and neuropathology. Curr Alzheimer Res 2012;9:724-33.

[32] Z. Arvanitakis, J.A. Schneider, R.S. Wilson, Y. Li, S.E. Arnold, Z. Wang, D.A. Bennett. Diabetes is related to cerebral infarction but to AD pathology in older persons. Neurology 2006;67:1960-65. 
[33] Z. Arvanitakis, D. A. Bennett, R.S. Wilson, L.L. Barnes. Diabetes and cognitive systems in older black and white persons. Alzheimer Dis Assoc Disord 2010;24:37-42.

[34] P.T. Nelson, C.D. Smith, E.L. Abner, F.A. Schmitt, S.W. Scheff, G.J. Davis, J.N. Keller, G.A. Jicha, D. Davis, W. Wang, A. Hartman, D.G. Katz, W.R Markesbery. Human cerebral neuropathology of Type 2 diabetes mellitus. Biochem Biophys Acta.2009;1792:454-69.

[35] M. Schütt, E. Fach, J. Seufert, W. Kerner, W. Lang, A. Zeyfang, R. Welp, R.W. Holl. Multiple complications and frequent severe hypoglycaemia in 'elderly' and 'old' patients with Type 1 diabetes. Diabetic Medicine 2012;29:e176-e179.

[36] J.A. Schneider, R.S. Wilson, J.L. Bienias, D.A. Evans, D.A. Bennett. Cerebral infarctions and the likelihood of dementia from Alzheimer disease pathology. Neurology 2004;62:1148-55.

[37] D. Erten-Lyons, R.L. Woltjer, H. Dodge, R. Nixon, R. Vorobik, J.F. Calvert, M. Leahy, T. Montine, J. Kaye. Factors associated with resistance to dementia despite high Alzheimer disease pathology. Neurology 2009;72:354-60.

[38] T.J. Montine, C.H. Phelps, T.G. Beach, E.H. Bigio, N.J. Cairns, D.W. Dickson, C. Duyckaerts, M.P. Frosch, E. Masliah, S.S. Mirra, P.T. Nelson, J.A. Schneider, D.R. Thal, J.Q. Trojanowski, H.V. Vinters, B.T. Hyman. National Institute on Aging-Alzheimer's Association guidelines for the neuropathological assessment of Alzheimer's disease: a practical approach. Acta Neuropathol 2012;123:1-11.

[39] M. Folstein, S.E. Folstein, P.R. McHugh. "Mini-Mental State": a Practical Method for Grading the Cognitive State of Patients for the Clinician. J Psych Res 1975;12:189-198.

[40] W.G. Rosen. Verbal fluency in aging and dementia. J Clin Neuropsych 1980; 2:135-146.

[41] A.R. Folsom, M.L. Rasmussen, L.E. Chambless, G. Howard, L.S. Cooper, M.I. Schmidt, G. Heiss. Prospective associations of fasting insulin, body fat distribution, and diabetes with risk of ischemic stroke: the Atherosclerosis Risk in Communities (ARIC) Study Investigators. Diabetes Care 1999;22:107783. 
[42] C. MacKnight, K. Rockwood, E. Awalt, I. McDowell. Diabetes mellitus and the risk of dementia, Alzheimer's disease and vascular cognitive impairment in the Canadian Study of Health and Aging. Dement Geriatr Cogn Disord 2002;14:77-83.

[43] T. Almdal, H. Scharling, J.S. Jensen, H. Vestergaard. The independent effect of type 2 diabetes mellitus on ischemic heart disease, stroke, and death: a population-based study of 13,000 men and women with 20 years of follow-up. Arch Intern Med 2004;164:1422-6.

[44] E.L. Air, B.M. Kissela. Diabetes, the metabolic syndrome, and ischemic stroke. Epidemiology and possible mechanisms. Diabetes Care 2007;30:3131-40.

[45] H. Mast, J.L.P. Thompson, S. Lee, J.P. Mohr, R.P. Sacco. Hypertension and diabetes mellitus as determinants of multiple lacunar infaracts. Stroke 1995;26:30-3.

[46] A. Akomolafe, A. Beiser, J.B. Meigs, R. Au, R.C. Green, L.A. Farrer, P.A. Wolf, S. Seshadri. Diabetes mellitus and risk of developing Alzheimer disease. Results from the Framingham Study. Arch Neurol 2006;63:1551-55.

[47] M. Yarchoan, J.B. Toledo, E.B. Lee, Z. Arvanitakis, H. Kazi, L.Y. Han, N. Louneva, V.M. Lee, S.F. Kim, J.Q. Trojanowski, S.E. Arnold. Abnormal serine phosphorylation of insulin receptor substrate 1 is associated with tau pathology in Alzheimer's disease and tauopathies. Acta Neuropathol 2014;128:67989.

[48] M. Vandal, P.J. White, C. Tremblay, I. St-Amour, G. Chevrier, V. Emond, D. Lefrançois, J. Virgili, E. Planel, Y. Giguere, A. Marette, F. Calon. Insulin reverses the high-fat diet-induced increase in brain A $\beta$ and improves memory in an animal model of Alzheimer disease. Diabetes 2014;63:4291-301.

[49] A.M. Rawlings, A.R. Sharrett, A.L. Schneider, J. Coresh, M. Albert, D. Couper, M. Griswold, R.F. Gottesman, L.E. Wagenknecht, B.G. Windham, E. Selvin. Diabetes in midlife and cognitive change over 20 years: a cohort study. Ann Intern Med 2014;161:785-93. 


\section{Tables}

Table 1. Demographic and clinical characteristics of autopsied SMART subjects with known diabetes status and available neuropathological data

\begin{tabular}{|c|c|c|c|c|}
\hline & $\begin{array}{c}\text { All subjects } \\
(\mathrm{N}=2,365)\end{array}$ & $\begin{array}{l}\text { Diabetes } \\
(\mathrm{N}=507)\end{array}$ & $\begin{array}{c}\text { No Diabetes } \\
(\mathrm{N}=1,858)\end{array}$ & $P$ value* \\
\hline Age at death, years & $88.7 \pm 6.5$ & $87.8 \pm 6.0$ & $89.0 \pm 6.6$ & $<0.0001$ \\
\hline Female (n [\%]) & $1009(42.7)$ & $147(29.0)$ & $862(46.4)$ & $<0.0001$ \\
\hline Education, years & $14.1 \pm 4.2$ & $13.7 \pm 4.2$ & $14.3 \pm 4.2$ & 0.002 \\
\hline Hypertension (n [\%]) & $1,600(67.7)$ & $413(81.5)$ & 1,187 (63.9) & $<0.0001$ \\
\hline APOE- $\varepsilon 4$ carrier (n [\%]) & $543(23.0)$ & $103(20.3)$ & $440(23.7)$ & 0.12 \\
\hline Last clinical diagnosis (n [\%]) & & & & 0.69 \\
\hline Intact cognition & $948(40.1)$ & $204(40.2)$ & $744(40.0)$ & \\
\hline Mild Cognitive Impairment & $473(20.0)$ & $95(18.7)$ & $378(20.3)$ & \\
\hline Dementia & $908(38.4)$ & $198(39.1)$ & $710(38.2)$ & \\
\hline Other/Unknown & $36(1.5)$ & $10(2.0)$ & $26(1.4)$ & \\
\hline MMSE, 6 years prior to death $\dagger$ & $27.0 \pm 3.8$ & $27.3 \pm 3.0$ & $26.9 \pm 4.0$ & 0.20 \\
\hline MMSE, $\leq 2$ years of death $\ddagger$ & $22.2 \pm 8.4$ & $21.9 \pm 8.4$ & $22.2 \pm 8.4$ & 0.58 \\
\hline Animals, 6 years prior to death§ & $15.0 \pm 5.6$ & $14.8 \pm 5.7$ & $15.1 \pm 5.6$ & 0.63 \\
\hline Animals, $\leq 2$ years of death $\emptyset$ & $10.7 \pm 6.1$ & $10.1 \pm 5.9$ & $10.9 \pm 6.1$ & 0.032 \\
\hline
\end{tabular}

*Comparisons are Diabetes vs. No Diabetes; diabetes is determined by self-report or report of antidiabetes medication use. †Diabetes, $n=179 ;$ No Diabetes, $n=746$. $\ddagger$ Diabetes, $n=244 ;$ No Diabetes, $n=1092$. §Diabetes, $n=200$; No Diabetes, $n=775$. ीDiabetes, $n=339$; No Diabetes, $n=1167$. Results presented are mean \pm standard deviation unless otherwise noted. 
Table 2. Cerebrovascular disease and Alzheimer's disease neuropathologies ( $N=2,365)$.

\begin{tabular}{|c|c|c|c|}
\hline Neuropathology (n [\%]) & $\begin{array}{l}\text { Diabetes } \\
(\mathrm{N}=507)\end{array}$ & $\begin{array}{c}\text { No Diabetes } \\
(\mathrm{N}=1,858)\end{array}$ & $P$ value* \\
\hline \multicolumn{4}{|l|}{ Cerebrovascular disease pathology } \\
\hline Any infarcts & $354(69.8)$ & 1,105 (59.5) & $<0.0001$ \\
\hline Missing any infarcts ${ }^{\dagger}$ & $24(4.7)$ & $62(3.3)$ & \\
\hline Large artery infarcts ${ }^{\ddagger}$ & $129(25.4)$ & 389 (20.9) & 0.034 \\
\hline Missing large artery infarcts & $2(0.4)$ & $16(0.9)$ & \\
\hline Lacunes $^{\S}$ & $283(55.8)$ & $749(40.3)$ & $<0.0001$ \\
\hline Missing lacunes & $4(0.8)$ & $24(1.3)$ & \\
\hline Microinfarcts ${ }^{\natural}$ & $140(27.6)$ & $519(27.9)$ & 0.11 \\
\hline Missing microinfarcts & $118(23.3)$ & $226(12.2)$ & \\
\hline Number of infarct types & & & $<0.0001$ \\
\hline 0 & $153(30.2)$ & $753(40.5)$ & \\
\hline 1 & $202(39.8)$ & $661(35.6)$ & \\
\hline 2 & $106(20.9)$ & $336(18.1)$ & \\
\hline 3 & $46(9.1)$ & $108(5.8)$ & \\
\hline \multicolumn{4}{|c|}{ Alzheimer's disease neuropathology } \\
\hline \multicolumn{4}{|l|}{ Braak NFT stage } \\
\hline $0 / 1 / I I$ & $160(31.6)$ & $512(27.6)$ & ref \\
\hline III/VI & $213(42.0)$ & $793(42.7)$ & 0.20 \\
\hline $\mathrm{V} / \mathrm{VI}$ & $102(20.1)$ & $418(22.5)$ & 0.08 \\
\hline Missing & $32(6.3)$ & $135(7.3)$ & \\
\hline \multicolumn{4}{|l|}{ CERAD neuritic plaque rating } \\
\hline None & $161(31.8)$ & $566(30.5)$ & ref \\
\hline Sparse & $110(21.7)$ & $374(20.1)$ & 0.86 \\
\hline Moderate & $154(30.4)$ & $566(30.5)$ & 0.42 \\
\hline Frequent & $82(16.2)$ & $384(20.7)$ & 0.022 \\
\hline Missing & 0 & 0 & \\
\hline \multicolumn{4}{|l|}{ Modified Alzheimer's ABC rating\# } \\
\hline No AD changes & $138(27.2)$ & $472(25.4)$ & ref \\
\hline Low AD changes & $149(29.4)$ & $481(24.9)$ & 0.67 \\
\hline Intermediate $A D$ changes & $119(23.5)$ & $462(24.9)$ & 0.37 \\
\hline High AD changes & $86(17.0)$ & $357(19.2)$ & 0.21 \\
\hline Missing & $15(3.0)$ & $86(4.6)$ & \\
\hline
\end{tabular}

${ }^{*} P$ values are for results of chi-square tests. +Participant has no recorded infarcts but is missing data for at least one infarct type. ¥One or more large artery cerebral infarcts. §One or more lacunes (small artery infarcts and/or hemorrhages). ๆOne or more cortical microinfarcts (including granular atrophy). \#High AD changes = presence any diffuse plaques plus Braak V/VI plus Frequent or Moderate neuritic plaques; Intermediate AD changes = presence of any diffuse plaques plus EITHER Braak V/VI plus None or Sparse neuritic plaques OR Braak III/IV plus Frequent or Moderate neuritic plaques; Low AD changes = presence of any diffuse plaques plus EITHER Braak III/IV plus None or Sparse neuritic plaques OR Braak 0/I/II; No AD changes = absence of diffuse plaques. 
Table 3. Adjusted odds ratios for diabetes given presence of cerebrovascular disease and Alzheimer's disease neuropathology.

\begin{tabular}{|c|c|c|}
\hline $\begin{array}{l}\text { Neuropathology } \\
\text { (Dependent variable) }\end{array}$ & $\begin{array}{l}\text { Model 1* } \\
\text { OR }(95 \% \mathrm{Cl})\end{array}$ & $\begin{array}{l}\text { Model } 2 \dagger \\
\text { OR }(95 \% \mathrm{Cl})\end{array}$ \\
\hline \multicolumn{3}{|l|}{$\begin{array}{l}\text { Cerebrovascular pathology } \\
\text { (present vs. absent) }\end{array}$} \\
\hline Any infarcts & $1.57(1.23,2.00)^{\ddagger \S}$ & $1.54(1.19,2.00)^{\ddagger \S}$ \\
\hline Large artery infarcts & $1.19(0.94,1.51)$ & $1.17(0.92,1.49)$ \\
\hline Lacunes & $1.71(1.39,2.12)^{\ddagger \S}$ & $1.77(1.42,2.20)^{\ddagger \S}$ \\
\hline Microinfarcts & $1.17(0.90,1.53)$ & $1.16(0.88,1.54)$ \\
\hline Three infarct types reported & $1.44(1.00,2.09)$ & $1.48(1.01,2.16)^{\ddagger}$ \\
\hline \multicolumn{3}{|l|}{ Alzheimer's disease pathology } \\
\hline \multicolumn{3}{|l|}{ Braak NFT stage } \\
\hline V/VI vs. $0 / 1 / I I$ & $0.82(0.61,1.11)$ & $0.97(0.70,1.35)$ \\
\hline III/IV vs. 0/I/II & $0.92(0.72,1.18)$ & $0.99(0.76,1.29)$ \\
\hline \multicolumn{3}{|l|}{ CERAD neuritic plaque rating } \\
\hline Frequent vs. None & $0.96(0.68,1.36)$ & $1.25(0.83,1.87)$ \\
\hline Moderate vs. None & $1.02(0.78,1.33)$ & $1.11(0.83,1.48)$ \\
\hline Sparse vs. None & $0.98(0.73,1.30)$ & $1.07(0.79,1.46)$ \\
\hline \multicolumn{3}{|l|}{ Modified Alzheimer's ABC rating } \\
\hline High vs. No AD changes & $1.05(0.76,1.46)$ & $1.13(0.77,1.65)$ \\
\hline Intermediate vs. No AD changes & $1.17(0.86,1.60)$ & $1.34(0.96,1.87)$ \\
\hline Low vs. No AD changes & $1.22(0.92,1.60)$ & $1.31(0.98,1.76)$ \\
\hline \multicolumn{3}{|c|}{$\begin{array}{l}\text { *Odds ratios are adjusted for age at death (centered at } 85 \text { ), female sex }(1,0) \text {, and research center (Honolulu-Asia } \\
\text { Aging Study, Oregon Health \& Science University, Rush University Medical Center, Washington University, or } \\
\text { University of Kentucky). }+ \text { In model } 2 \text {, years of education, history of hypertension }(1,0) \text {, and APOE- } \varepsilon 4 \text { carrier status } \\
(1,0) \text { are included as additional control variables. } ¥ P \text { value significant at } 0.05 \text {. } § P \text { value statistically significant after } \\
\text { applying Holm-Bonferroni procedure. }\end{array}$} \\
\hline
\end{tabular}


Table 4. Adjusted end-of-life mean Mini-Mental State Examination (MMSE) and Animal Naming (Animals) scores*

\begin{tabular}{lcc}
\hline Participant group & $\begin{array}{c}\text { MMSE } \\
(\mathrm{n}=1,317)\end{array}$ & $\begin{array}{c}\text { Animals } \\
(\mathrm{n}=1,335)\end{array}$ \\
\hline (1) Diabetes + any infarcts & $20.8(0.4)^{\dagger, \ddagger, \S}$ & $9.4(0.3)^{\dagger, \ddagger, \S}$ \\
(2) No Diabetes + any infarcts & $21.9(0.3)^{\natural}$ & $10.0(0.2)^{\natural}$ \\
(3) Diabetes + no infarcts & $24.9(0.5)$ & $11.5(0.4)$ \\
(4) No Diabetes + no infarcts & $23.7(0.3)$ & $11.3(0.2)$ \\
\hline Participant group & MMSE & Animals \\
\hline (1) Diabetes + lacunes & $(\mathrm{n}=1,302)$ & $(\mathrm{n}=1,128)$ \\
(2) No diabetes + lacunes & $20.8(0.5)^{\dagger, \ddagger, \S}$ & $10.1(0.4)^{\dagger, \ddagger, \S}$ \\
(3) Diabetes + no lacunes & $22.2(0.3)^{* *}$ & $11.0(0.3)^{\natural}$ \\
(4) No diabetes + no lacunes & $24.3(0.5)$ & $12.5(0.4)$ \\
\hline
\end{tabular}

*Scores obtained within two years of death. Results are mean (SEM). Means are adjusted for modified $A B C$ rating, age at death, education, female sex, research center, and time between last assessment and death. $\dagger$ (1) vs. (2) $P<0.05 \ddagger(1)$ vs. (3) $P<0.0001$. §(1) vs. (4) $P<0.0001$. П(2) vs. (4) $P<0.0001$. \#(1) vs. (2) $P<0.05^{* *}(2)$ vs. (4) $P<0.05$. 


\section{Figures}

Figure 1. Participant inclusion flow diagram

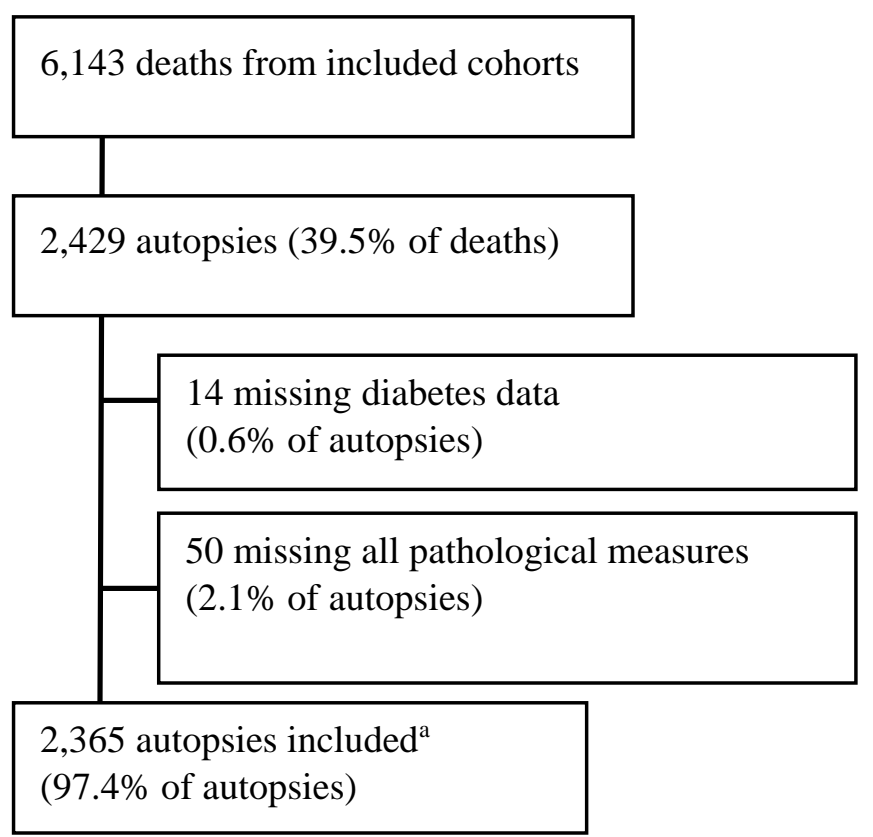

a. Honolulu-Asia Aging Study ( $n=769$ ), the Oregon Brain Aging Study I and II ( $n=77$ and 32), the African American Dementia Project $(n=1)$, the Klamath Exceptional Aging Project $(n=80)$, the Religious Orders Study ( $n=555)$, the Memory and Aging Project at Rush University Medical Center $(n=454)$, the Memory and Aging Project at Washington University $(n=126)$, and the Biologically Resilient Adults in Neurological Studies $(n=271)$. 